\title{
Firm Location when Countries Differ in Infrastructures or Incomes
}

\author{
Ana M. Martín-Arroyuelos and José M. Usategui \\ Universidad del País Vasco (UPV-EHU)
}

\begin{abstract}
This paper analyzes, in a linear market with two adjacent countries, how firm location and optimal plant size depend on differences in the quality of infrastructures and income levels between countries. The study consi ders also how a free trade agreement may change, in this context where geography is made explicit, the country where a firm locates and discusses when variations in infrastructures or incomes provide incentives for firm delocation. Among the results we obtain that an increase in income in the country with lower income may induce a firm to locate in the other country and that an increase in the difference in qualities of infrastructures between countries or a free trade agreement may move the optimal location of a firm from the country with worst infrastructure to the country with better infrastructure. (JEL Classifications: R30, F23) ४Key Words: firm location, infrastructure, income

* Correspondence Address: Dep. Economía Aplicada III (M artín-Arroyuelos)-D ep. Fundamentos del Análisis Económico (Usategui). Universidad del País Vasco. Avda. Lehendakari Agirre, 83. 48015 Bilbao. Spain. (Tel) +34-94-6013771, (Fax) +34-946013774. (E-mail) etpmaara@bs.ehu.es (M artín-Arroyuelos), Jepusdij@bs.ehu.es (U sategui).

Research support from the M inistry of Education of Spain (DGES PB97-0603) and from the Basque Government (project PI-1998-86) is gratefully acknowledged. We thank an anonymous referee for helpful suggestion.
\end{abstract}

(C2000 - Center for International Economics, Sejong Institution. All rights reserved. 
differences, linear market, economic integration.>

\section{Introduction}

This work focuses on the effects on firm location and optimal plant size of differences in the quality of infrastructures and in income levels between countries. The effects of the quality of infrastructures and of the levels of income have not been analyzed previously in a context where geography is made explicit within each country. We show in this work the relevance of considering these factors to study firm location (and firm delocation), optimal plant size and the consequences of a free trade agreement.

We are interested first in knowing how firm location and optimal plant size depend on differences in the quality of infrastructures or incomes. $M$ oreover, we want to learn how changes in these variables affect firm location and optimal plant size. This latter analysis is important to evaluate the impact of policies that affect infrastructures or incomes. If the firm is already installed when the variations in the quality of infrastructures or incomes occur we want to know when there are incentives for firm delocation from one country to the other. Although there are other factors relevant for these decisions the factors emphasized in this paper deserve attention as their impact may be important and is non trivial

We also want to analyze the effect on firm location and optimal plant size of a Free Trade Agreement between the two countries. Free trade agreements are becoming an increasingly extended reality: the European Union, the N orth-America F ree Trade Agreement (US-Canada-M exico), M ercosur in South-America and ASEAN in the Asia-Pacific area are well known examples of this reality. The consequences of these agreements for firm location and for firm delocation within the same free trade area, however, have not been fully analyzed. In this paper we study the effects of a free trade agreement when there are differences in incomes or geographical accessibility (quality of infrastructures) between countries

The analysis in this paper may serve to study what effect a policy that improves infrastructure in a country will have on industrial location or to design income convergence policies to attract firms into the country with lower income. Our work may also be used to predict the effects of a free 
trade agreement on firm location or firm delocation

We consider a firm that is the only producer of a good, may be because it has a patent on the good. This firm wants to install a unique plant and has to choose location within one of the two countries where the good produced by the firm may be sold. The firm may belong to one of these two countries or to a third countr $y$. $M$ anagement and coordination costs between different plants may be the reason for the decision to install a unique plant

In the analysis we assume a linear market in which the two countries are adjacent. Countries are not dimensionless points as it is costly to transport one unit of the good from any location to any other location within the same country or between countries. Hence, geography is made explicit as countries have a spatial representation with a location, a size and a cost to transport the good along the space (see Krugman [1991a])

The quality of infrastructures in a country affects costs of trade within this country and between countries. In our model these costs take the form of transport costs related to distance. Geography and past investments may explain differences in the quality of infrastructures between countries. ${ }^{1}$

On the other hand, income differences may be due to distinct degrees of economic development in the two countries. In this work, differences in incomes will be represented by differences in willingness to pay for the good produced by the firm. ${ }^{2}$

We consider the production cost independent of the location of the firm and, hence, assume away explanations of the firm location based on factor prices and factor availability. Moreover, we do not discuss public policies towards business and, therefore, suppose that these policies do not affect the location decision of the firm. ${ }^{3}$

1. Bougheas, Demetriades and M orgenroth [1999] contains an analysis, in a different context, of the relationship between investment in infrastructures, transport costs and the volume of trade.

2. As an improvement in the quality of infrastructure in a country facilitates trade within this country and between countries its impact will be through demand as it occurs with an increase in the income level.

3. See Holmes [1998] and Haufler and Wooton [1999] for recent analysis on this direction. The case of environmental dumping, that has been used to explain firm delocation (see M otta and Thisse [1994]) is, therefore, also assumed away. 
When we analyze how firm location and optimal plant size depend on differences in the quality of infrastructures or incomes between countries and how changes in these variables affect firm location and optimal plant size we consider a context where there are not tariffs on exports from one country to the other. This is the relevant context when we desire to study income or infrastructure policies within a free trade area, as it is the case of policies for income convergence or infrastructure convergence between countries within the European Union. ${ }^{4}$ However, the analysis of the case with tariffs is immediate from the developments presented and we use it to study the effects of a free trade agreement.

We obtain first how firm location and market coverage depend on transport costs and incomes (Propositions 1 and 2). As we expected when countries differ only in transport costs (incomes) the optimal location of the firm may be in the country with higher transport cost (lower income). Hence, the firm may not locate in the country with higher income or with better infrastructure. However, this is contrary to the results obtained in other analysis of industrial location based on different models. ${ }^{5}$

When transport costs differ between countries we obtain how the effects of changes in transport costs depend on the quantity of these changes, on the income level and on the initial relative transport costs of the two countries. For instance, we obtain that an increase in the difference of transport costs between countries may move the optimal location of the firm from the country with lower transport cost to the country with higher transport cost. In particular, the effects of variations in transport costs may be different if, as a consequence of these variations, the country with higher transport cost becomes the country with lower transport cost. This analysis can be used to study what effect a policy that improves infrastructure in a country will have on industrial location.

When incomes differ between countries we prove that policies that

4. The Structural Funds and the Cohesion Funds in the European Union are policies oriented to promote infrastructure convergence and, more indirectly, income convergence among countries in this free trade area.

5. For instance, Martin and Rogers [1995] obtain that a policy of financing domestic infrastructure in a country will bring industrial location to this country. 
increase incomes in both countries or in the country with lower income may change the optimal location of the firm from the country with lower income to the country with higher income and, hence, these policies will not necessarily attract firms into the country with lower income. This result is obtained in a context where the country with lower income remains as the country with lower income after the increase in its income. We show how the effect of a change in income within a country depend on the quantity of this change, the transport cost, the initial relative incomes of both countries and any variation in income in the other country. If the aim of a policy is to foster industrial convergence between a rich and a poor country these results should be considered.

We also study the implications of transport cost or income convergence for firm location. If the transport costs converge, the optimal location of the firm may move only from the country with lower transport cost to the country with higher transport cost. However, if incomes converge there are situations where the optimal location of the firm changes from the country with lower income to the country with higher income.

Finally, considering that the countries have different qualities of infrastructures, we derive (Proposition 3) when a free trade agreement may induce a change in the optimal location of the firm from one country to the other. This analysis can be reproduced for the case where the countries differ in incomes. ${ }^{6}$

The paper is organized as follows: Section II presents the basic model. Section III analyzes the decisions of the firm on location and price (hence, on market coverage) when the countries differ in transport costs. The firm decisions when the countries differ in incomes are studied in Section IV. Section $V$ centers on the implications for firm location and firm delocation of changes in transport costs or incomes. The effects of a Free Trade Agreement on the location of the firm are considered in Section VI. The last section summarizes the results

6. See Venables [1995] and Krugman [1991b] for other aspects relevant to the relationship between economic integration and the location of firms. 


\section{Model}

Consider a linear market of length 1 which extends over two countries $A$ and B. Country A takes up from 0 to $\frac{1}{2}$ and country $B$ occupies from $\frac{1}{2}$ to 1 . Hence, $\frac{1}{2}$ is the frontier between the two countries and they have equal size

Consumers are uniformly distributed between 0 and 1 with unit density. Each consumer buys one unit of the good if the sum of the price and the transport cost is lower than or equal to the reservation value of the good for the consumer, and zero units otherwise. We consider that consumers within each country are identical and that consumers in different countries may differ only in their reservation values. Let us denote by $M_{1}$ the reservation value of each consumer in country I with $I \in\{A, B\}$. We assume that preferences are such that $M_{j}<M_{1}$ if and only if country $I$ has higher income or is the richest country

It is costly to transport the good along the market. It costs $t_{1}$ per unit of distance to transport one unit of good in country I with $I \in\{A, B\}$. We assume linear transport costs

A firm, which is the only producer of a homogeneous good, may locate in this linear market at any s such that $s \in\{0,1\}$. It produces the good with constant marginal cost which is assumed independent of location and, without loss of generality, equal to 0 . This firm decides first on location and afterwards it selects a nondiscriminatory (f.o.b.) selling price, $p$, to maximize its profits, $\pi$. The decisions on location and price determine if the market is covered or not. The firm is completely informed about consumers' reservation prices and about transport costs

\section{Decisions When Transport Costs Differ}

Consider that $t_{1}<t_{j}$ and $M_{1}=M_{J}=M$ with $I, J \in\{A, B\}$ and $I \neq J$. In this situation there are five possible results in terms of market coverage and location of the firm: 1) the firm covers only part of country I, 2) the firm covers completely country I and it does not supply to consumers in country J, 3) the firm covers countr y I and part of country J with location in countr y I, 4) the firm covers country I and part of country J with location in country J and 5) the firm covers the whole market with location in country J. 
In this context we can prove:

Proposition 1 : F or $\mathrm{I}, J \in\{\mathrm{A}, \mathrm{B}\}$ and $\mathrm{I} \neq \mathrm{J}$, when transportation costs dif fer between countries and $t_{1}<t_{j}$ the results in terms of market coverage and firm location will be:

i) when $M<\frac{t_{l}}{2}$ the firm will locate in I and will cover completely country I (case 1 ),

ii) when $\frac{t_{I}}{2} \leq M \leq \frac{t_{I}+t_{J}}{4}$ the firm will locate in I and will cover completely country I but it will not supply to consumers in country J (case 2),

iii) when $\frac{t_{t}+t_{J}}{4}<M \leq \frac{3 t_{t}+t_{j}}{4}$ the firm will locate in country I and will cover completely this country and part of country J (case 3),

iv) when $\frac{3 t_{t}+t_{J}}{4}<M<\frac{3 t_{t}+t_{3}}{4}$ the firm will locate in country J and will cover part of this country and completely country J (case 4), and

v) when $\frac{3 t_{+}+t_{3}}{4}<M$ the firm will locate in J and will cover the whole market (case 5).

Proof: See the Appendix.

From Proposition 1 it is immediate to obtain:

Corollary: For $\mathrm{I}, \mathrm{J} \in\{\mathrm{A}, \mathrm{B}\}$ and $\mathrm{I} \neq \mathrm{J}$, when transportation costs differ between countries and $t_{1}<t_{\text {j }}$ the firm will locate in country $I$ if and only if $M \leq \frac{3 t+t s}{4}$ :

Figure 1 illustrates Proposition 1 showing the zones where each case occurs. We have denoted by 1 to 5 the cases for $t_{1}<t_{1}$ and by $1^{\prime}$ to $5^{\prime}$ the (symmetric) cases for $t_{1}<t_{1}$. The dashed zone corresponds to the pairs ( $t_{1}$, $t_{j}$ ) implying that the firm will locate in J. In the rest of situations the firm will locate in 1.

\section{Decisions When Incomes Differ}

Conside that $M_{J}<M_{1}$ and $t_{1}=t_{j}=t$ with $\mathrm{I}, J \in\{A, B\}$ and $I \neq J$. The possible results in terms of market coverage and location of the firm that we may obtain are the same ones than in the context of differences in transport costs and we use the same notation for the five cases: 1, 2, 3, 4 and 5.

In this context we can prove: 
Proposition 2: $F$ or $I, J \in\{A, B\}$ and $I \neq J$, when incomes differ between countries and $M_{J}<M_{1}$ the results in terms of market coverage and firm loca tion will be:

i) when $M_{I}<\frac{t}{2}$ the firm will locate in I and will cover only part of country I (case 1),

ii) when either $\frac{t}{2} \leq M_{I}<\frac{5}{4} t$ and $M_{J} \leq-M_{I}+\sqrt{4 t M_{I}-t^{2}}$ or $M_{I} \geq \frac{5}{4} t$ and $M_{J} \leq \frac{M_{I}}{2}+\frac{t}{8}$ the firm will locate in I and will cover completely country I but it will not supply to consumers in country J (case 2),

iii) when $-M_{I}+\sqrt{4 t M_{I}-t^{2}} \leq M_{J}$ and $3 M_{I}-M_{J} \geq 2 t$ the firm will locate in country I and will cover completely this country and part of country J (case 3),

iv) when $-M_{I}+\sqrt{4 t M_{I}-t^{2}} \leq M_{J}, M_{I}+M_{J} \leq 2 t$ and $3 M_{I}-M_{J} \geq 2 t$ the firm will locate in countr $y \mathrm{~J}$ and will cover part of this country and completely country country I (case 4$)$, and

v) when $M_{I}+M_{J} \geq 2 t$ and $\frac{M_{I}}{2}+\frac{t}{8} \leq M_{J}$ the firm will locate in J and will cover the whole market (case 5).

Proof: See the Appendix.

From Proposition 2 it is immediate to obtain:

Corollary: For $\mathrm{I}, J \in\{A, B\}$ and $I \neq J$, when incomes differ between coun tries and and $M_{J}<M_{1}$ the firm will locate in country $I$ if and only if at least one of the following conditions occurs:

i) $M_{J} \leq-M_{I}+\sqrt{4 t M_{I}-t^{2}}$

ii) $3 M_{I}-M_{J} \leq 2 t$, and

iii) $M_{J} \leq \frac{M_{I}}{2}+\frac{t}{8}$

Figure 2 illustrates Proposition 2 showing the zones where each case occurs. We have denoted by 1 to 5 the cases for $M_{1}<M_{\text {J }}$ and by $1^{\prime}$ to $5^{\prime}$ the (symmetric) cases for $M_{3}<M_{1}$. The dashed zone corresponds to the pairs $\left(M_{1}, M_{\jmath}\right)$ implying that the firm will locate in $\mathrm{J}$. In the rest of situations the firm will locate in I.

Zones 3 and 4 in Figure 2 (and the symmetric zones $3^{\prime}$ and $4^{\prime}$ ) deserve particular attention. From the proof of Proposition 2 we have that in zones 3 
and 4 market coverage and price increase with $M_{\text {J }}$ but location moves to the

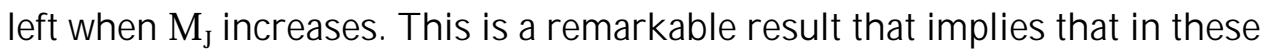
zones an increase in the income of the poorest country may induce the firm to locate in the other country. This possibility will be important in the analysis developed in subsection V.B below

\section{Changes in Transport Costs or Incomes and Their Implications}

In this section we discuss how variations in transport costs or incomes may imply that the optimal location of the firm changes from one country to the other. We may consider a situation where the firm has not decided yet its location and each country is interested in knowing if policies that modify transport costs or incomes may change the country of location of the firm.

Alternatively, we could consider that the firm is located according to the results in Propositions 1 or 2 . This firm may have been producing the good during several periods at that location. However, there is a variation in transport costs or incomes that, from Propositions 1 and 2, changes the optimal location. This variation was unexpected when the original location was decided or it was uncertain and far in the future (heavily discounted) at that moment. After the variation in transport costs or incomes the firm will change its location if the costs of relocation are lower than the present value of the increase in expected profits (assuming risk neutrality) in the future. If this relocation implies that the firm translates its location to the other country there will be firm delocation. To know if there are incentives for firm delocation we study when the variation in transport costs or incomes implies a change in the optimal location of the firm from one country to the other.

\section{A. Analysis When Transport Costs Differ}

Consider that $\mathrm{t}_{1}<\mathrm{t}_{\mathrm{J}}$ and $\mathrm{M}_{\mathrm{I}}=\mathrm{M}_{\mathrm{J}}=\mathrm{M}$ with $\mathrm{I}, \mathrm{J} \in\{A, \mathrm{~B}\}$ and $\mathrm{I} \neq \mathrm{J}$. In this case, we know from Corollary 1 that the optimal location of the firm depends on $\frac{3 t_{I}+t_{J}}{M}$ (with $\mathrm{t}_{1}<\mathrm{t}_{\mathrm{j}}$ ). If this fraction decreases the optimal location of the firm may change from country I to country $J$ and if this fraction increases the optimal location of the firm may change from country $\mathrm{J}$ to 
country I. The fraction $\frac{3 t_{1}+t_{J}}{M}$ decreases if $M$ increases and there is no variation in transport costs, and if $t_{1}$ and/ or $t_{1}$ decrease and $M$ remains unchanged. But $\frac{3 t_{1}+t_{J}}{M}$ may also decrease if a decrease in $M$ is accompanied by a higher decrease in $3 t_{1}+t_{1}$, if an increase in $3 t_{1}+t_{j}$ is accompanied by a higher increase in $M$ or if $t_{1}$ and $t_{j}$ move in opposite directions but $3 t_{1}+t_{j}$ decreases. ${ }^{7}$

From Proposition 1 we shoud notice, however, that a decrease in the transport cost within the country with higher transport cost will attract firms into this country or will expel firms away from this country depending on the quantity of this decrease, on $M$ and on the initial relative transport costs of both countries. The reason is that changes in transport costs may be such that the country that initially had higher transport cost becomes the country with lower transport cost. Consider that initially $t_{1}<t_{\text {J }}$. From Figure 1 we have that if $t_{j}$ decreases, with $t_{1}$ and $M$ unchanged, and if country J becomes the country with lower transport cost, the optimal location of the firm may change from country J (zones 4 and 5) to country I (zone 5'). On the contrary, we know from the previous paragraph that a decrease in any transport cost, with $\mathrm{M}$ unchanged and such that after the change in transport costs $t_{1}<t_{1}$, could only cause a change in the optimal location of the firm from country I to country $\mathrm{J}$ (a decrease in $t_{\text {j }}$ could only change the optimal location from country I, zone 3, to country J, zones 4 and 5).

M oreover there are situations (zones 1, 2 and 3 ) where an increase in $t_{1}$ induces a change in optimal location from country I to countr y J. Consider in Figure 1 that $\mathrm{t}_{1}$ increases, with $\mathrm{t}_{j}$ and $\mathrm{M}$ unchanged, and that country $\mathrm{I}$ becomes the country with higher transport cost. In this situation the new optimal location of the firm will be in countr $y$ J, except in the case where the market was initially covered (zone 5 ) as in this case the new optimal location may be in country I

In Figure 1 we can track the changes in optimal location of the firm (and in market coverage) as transportation costs evolve from any initial situation.

7. From Proposition 1 we know how the decisions on firm location and on market coverage are related. The effect of the variations in $M, t_{t}$ and $t_{j}$ on firm location derives from the changes in market coverage opportunities. 


\section{Figure 1}

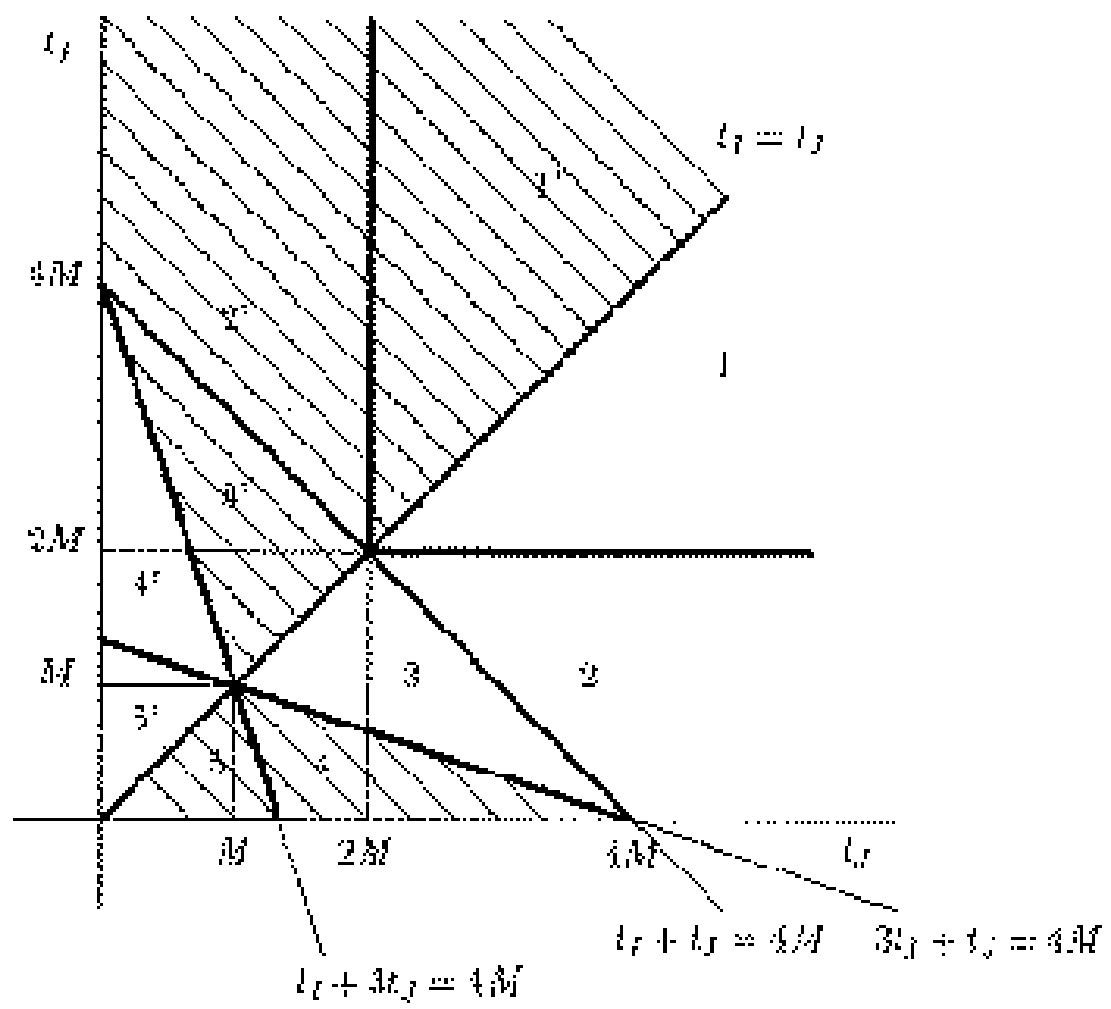

\section{B. Analysis When Incomes Differ}

Consider that $\mathrm{M}_{\mathrm{J}}<\mathrm{M}_{\mathrm{I}}$ and $\mathrm{t}_{\mathrm{l}}=\mathrm{t}_{\mathrm{f}}=\mathrm{t}$ with $\mathrm{I}, \mathrm{J} \in\{\mathrm{A}, \mathrm{B}\}$ and $\mathrm{I} \neq \mathrm{J}$. In this case, if $t, M_{1}$ and $M_{1}$ change in the same proportion the optimal location of the firm will not be affected. However, a variation in $t$ with both incomes unchanged may cause a change of the optimal location from one country to the other as a variation in $t$ implies a move in Figure 2 along the ray that goes through the origin and through the point representing the initial situation. $^{8}$

From Corollary 2 and Figure 2 it is clear that if the countries become richer ( $M_{1}$ and $M_{j}$ increase) the optimal location of the firm may change

8. A decrease in t implies a move away from the origin and, hence, may change the optimal location of the firm from country I to country J as we expected. 
Figure 2

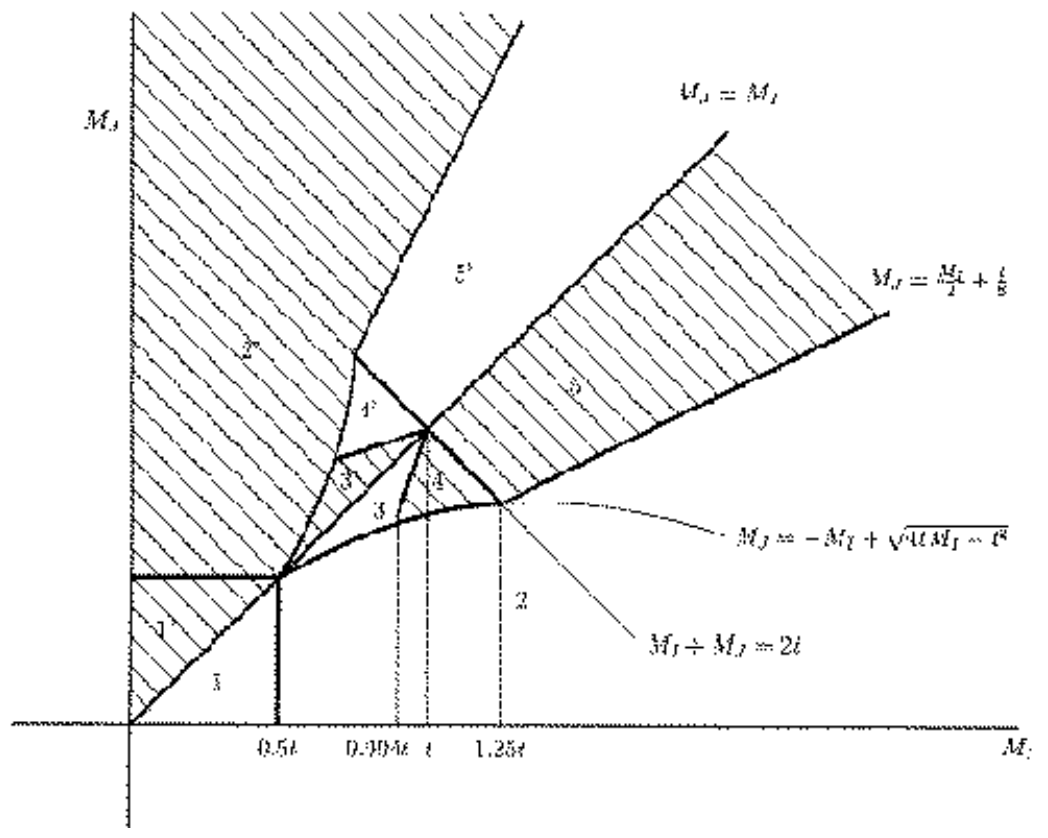

from the country with higher income to the country with lower income (for instance, a move from zone 2 to zones 4 or 5 implying an increase in market coverage). However, the opposite result is also feasible as we may move in Figure 2 from zones 4 and 5 to zone 2 if $M_{1}$ increases more than $M_{j}$ (the firm prefers to cover only market I where income has increased more and the price charged may be higher). Moreover, we see in Figure 2 that an increase in $M$, may change the optimal location of the firm to country J (a move from zone 2 to zones 4 or 5 ). N evertheless, there are other possibilities: Consider that $M_{1}=0.95$ t and $M_{\text {J }}$ is such that we are in zone 4 . As $M_{\text {J }}$ increases we may move into zone 3 implying an optimal location in country I. Hence, policies that increase incomes in both countries or in the country with lower income will not necessarily attract firms into this country. These policies may induce the firm to locate in the country with higher income.

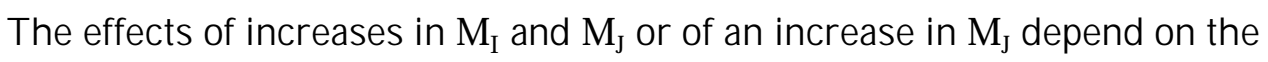
quantities of these increases, on $t$ and on the initial relative incomes of both countries, as a consequence of Proposition 2

Changes in income may be such that the country that initially had lower 
income becomes the country with higher income. Consider that initially $M_{1}$ $>M_{\text {J }}$. From the proof of Proposition 2 and Figure 2 we have that if initially the firm is located in $I, M_{1}>0.712 t$ and $M_{1}$ increases, with $M_{1}$ and $t$ unchanged, in such a way that country $\mathrm{J}$ becomes the country with higher income the optimal location of the firm may remain in I. The rest of possibilities corresponding to the situation where the country with lower income becomes the country with higher income follow immediately from Proposition 2 and Figure 2

In Figure 2 we can track the changes in optimal location of the firm (and in market coverage) as countries incomes evolve from any initial situation

Therefore, we have shown when variations in transport costs or in incomes may change the optimal location of the firm from one country to the other. If the firm is already located when the variations in transport cost or incomes happen there may be firm delocation. The occurrence of firm delocation will depend on relocation costs and on expected future variations in transport costs and incomes. If transport costs converge ( $t_{j}$ approaches $t_{1}$ ) the optimal location of the firm may move from country I (zone 3 in Figure 1) to country J (zones 4 or 5 ) but not from country J to country I. If incomes converge $\left(M_{1}\right.$ approaches $\left.M_{1}\right)$ the optimal location of the firm may move from country I (zone 2 in Figure 2) to country J (zones 4 or $5 \%$ ) but also from country J (zone 4 in Figure 2 with $0.904 t<M_{1}<t$ ) to country I (zone 3)

\section{Effects of a Free Trade Agreement}

When two countries decide to start a process of integration a usual first step is a mutual tariff reduction. Consider an initial situation where country $A$ has established a fixed- quantity tariff $f_{A}$ on imports from country $B$ and country $B$ has established a per unit tariff $f_{B}$ on imports from country $A$. With tariffs there are two additional results in terms of market coverage and optimal location of the firm, besides 1 to 5 . In this context we may also have: $3^{*}$ ) the firm covers country I and part of country J with location on the Iside of the frontier between the two countries and $4^{*}$ ) the firm covers country I and part of country J with location on the J-side of the frontier. In this section we analyze when a free trade agreement may induce a change in the optimal location of the firm from one country to the other. We consider that 
the countries have different transport costs (the study would be analogous if the countries differ in incomes). In this context we can prove:

Proposition 3 : For $I, J \in\{A, B\}$ and $I \neq J$, consider that $f_{l}$ and $f_{j}$ are the per unit tariffs set, respectively, by countries $I$ and $J$, respectively, and that $t_{1}<t_{1}$ and $M_{1}=M_{J}=M$. A free trade agreement may change the optimal location of the firm::

i) from country $\mathrm{J}$ to country I only if $f_{J}>f_{I}+\frac{f_{I}^{2}}{M}$,

ii) from country $I$ to country $J$ in the rest of situations.

\section{Proof: See the Appendix}

As it is shown in the proof of Proposition 3 result ii) corresponds to a situation where we have case $4^{*}$ with tariffs and case 3 without tariffs. On the other hand result i) cor responds to a situation where we have case 2 or case $3^{*}$ with tariffs and case 4 without tariffs. From Proposition 3 we know when a free trade agreement may change the optimal location of the firm from the country with lower transport cost to the other country or viceversa.

\section{Conclusion}

In this paper we have analyzed how firm location and optimal plant size depend on differences in the quality of infrastructures and income levels between countries and how changes in these variables affect firm location and optimal plant size. From this analysis we have extended the study to consider how a free trade agreement may change the country where a firm locates when quality of infrastructures or incomes differ between countries and to discuss when variations in infrastructures or incomes provide incentives for firm delocation.

We have assumed a linear market where there are two adjacent countries. Geography has been made explicit as countries have a spatial representation with a location, a size and a cost to transport the good within each country and between countries.

Among other results obtained, we have shown in this work how a firm may not locate in the country with higher income or with better infrastructure, how an increase in income in the country with lower income (or in 
both countries) may induce a firm to locate in the other country, how an increase in the difference in the qualities of infrastructures between countries may move the optimal location of a firm from the country with worst infrastructure to the country with better infrastructure or when a free trade agreement may induce a change in the optimal location of the firm from the country with lower transport cost to the country with higher transport cost or viceversa. O ur study has stressed the importance of the initial conditions to analyze the effects on firm location and market coverage in each country of a free trade agreement or of variations in the qualities of infrastructures or in income levels.

This analysis may serve to study what effect a policy that improves infrastructure in a country will have on industrial location or to design income convergence policies to attract firms into the country with lower income. The results obtained may also be relevant for countries that have decided to integrate by forming a free trade area. We can emphasize the importance of considering the foreseeable evolution of countries incomes and infrastructures after integration as this evolution will have consequences in terms of firms location.

The effects of the quality of infrastructures and of the levels of income have not been analyzed previously in a context where geography is made explicit within each country. We have shown in this work the relevance of considering these factors to study firm location (and firm delocation), optimal plant size and the consequences of a free trade agreement.

\section{References}

Bougheas, S., Demetriades, P.O. and E.L.W. M orgenroth [1999], "Infrastructure, Transport Costs and Trade," Journal of International Eco nomics 47; pp. 169-189.

Haufler, A. and I. Wooton [1999], "Country Size and Tax Competition for Foreign Direct Investment," Journal of Public Economics 71; pp. 121139.

Holmes, T. J. [1998], "The Effect of State Policies on the Location of M anufacturing: Evidence from State Borders," Journal of Political Economy 106(4); pp. 667-705. 
Krugman, P. [1991a], Geography and Trade, Leuven University Press, Leuven, and The MIT Press, Cambridge.

Krugman, P. [1991b], "Increasing Returns and Economic Geography," Jour nal of Political Economy 99(3); pp. 483-499.

Martin, P. and C.A. Rogers. [1995], "Industrial Location and Public InfraStructure," Journal of International Economics 39; pp. 335-351.

M otta, M . and Thisse, J.F . [1994], "D oes Environmental Dumping Lead to

Delocation?," E uropean E conomic Review 38; pp. 563-576.

Venables, A. [1995], "Economic Integration and the Location of Firms," American Economic Review 85(2); pp. 296-300.

\section{Appendix}

\section{A.1 Proof of Proposition 1}

i) to v):

We derive the proof for the case $t_{1}<t_{1}$ with $I, J \in\{A, B\}$.

In case 1 the firm will be indifferent between an interval of locations. The extremes of this interval are those locations such that, at the corresponding optimum price, the consumer located at 0 (for the left extreme of the interval) and the consumer located at $\frac{1}{2}$ (for the right extreme of the inter val) get no surplus. Taking the left extreme of this inter val we have $p=$ $M-t_{1} . s$ and $\pi=p .2 s$. From profit maximization we obtain for this left extreme of the interval $s=\frac{M}{2 t_{I}}$ and $=\frac{M^{2}}{2 t_{I}}$. Hence, the interval of locations will be $\left[\frac{M}{2 t_{I}}, \frac{1}{2}-\frac{M}{2 t_{I}}\right]$. Case 1 results when $\frac{1}{4}>\frac{M}{2 t_{I}}$, i.e., when $\frac{t_{l}}{2}>M$.

In case 2 it will be $s=\frac{1}{4}, p=M-\frac{t_{l}}{4}$ and $=\frac{M}{2}-\frac{t_{I}}{8}$. This alternative will occur when $\frac{t_{l}}{2} \leq M \leq \frac{t_{l}+t_{J}}{4}$. When $M<\frac{t_{I}}{2}$ we were in case 1 and when $\frac{t_{1}+t_{J}}{4}<M$ the good will be supplied to consumers in country $\mathrm{J}$.

In case 3 the consumer $\mathrm{z}$ in $\mathrm{J}$ that will be indifferent between buying and not buying the good will be such that $M=p+t_{I}\left(\frac{1}{2}-s\right)+t_{J}\left(z-\frac{1}{2}\right)$. As $p=M-t_{I} s$ (the consumer at 0 gets no surplus in the solution that maximizes the firm's profits), we obtain from profit maximization ( $\pi=p . z)$ that $s=\frac{M}{2 t_{I}}+\frac{t_{I}-t_{I}}{8 t_{I}}$. This alternative requires $\frac{1}{4}<s=\frac{M}{2 t_{I}}-\frac{t_{J}-t_{I}}{8 t_{I}}$, i.e., $\frac{t_{I}+t_{J}}{4}<M$ (this condition will also imply $z>\frac{1}{2}$ ). M oreover, $\sin$ I implies $s \leq \frac{1}{2}$, i.e., $M \leq \frac{3 t_{t}+t_{j}}{4}$. 
Hence, this solution will result when $\frac{t_{l}+t_{J}}{4}<M \leq \frac{3 t_{l}+t_{J}}{4}$.

In case 4 we proceed as in the previous case and, noting that the indifferent consumer in $\mathrm{J}$ is $z=\frac{t_{I}}{2 t_{J}}+2 s-\frac{1}{2}$, obtain $s=\frac{2 M+\frac{2}{3}\left(t_{J}-t_{I}\right)}{4 t_{J}}$. As $\mathrm{s}$ in J requires $s \geq \frac{1}{2}$ it should be $\frac{3 t_{t}+t_{J}}{4} \leq M$. Moreover, in this case $z<1$, i.e., $M<\frac{3 t_{f}+t_{t}}{4}$. Hence, this solution will result when $\frac{3 t_{l}+t_{J}}{4} \leq M<\frac{3 t_{J}+t_{I}}{4}$.

Finally, in case 5 the firm will locate in J. As profit maximization in a covered market implies that the consumers located in the extremes of the market get no surplus we obtain $s=\frac{4 t_{1}-t_{J}}{4 t_{J}}$ (notice that $s>\frac{1}{2}$ ) and $=p=M-\frac{t_{l}+t_{j}}{4}$. The market will be covered only when $M \geq \frac{3 t_{J}+t_{I}}{4}$.

\section{A.2 Proof of Proposition 2}

i) to v):

We derive the proof for the case $M_{j}<M_{1}$ with $I, J \in\{A, B\}$.

For case 1 we reason as in the proof of Proposition 1 and obtain $s=\frac{M_{I}}{2 t}$, $=\frac{M_{I}^{2}}{2 t}$ and $s \in\left[\frac{M_{I}}{2 t}, \frac{1}{2}-\frac{M_{I}}{2 t}\right]$. This alternative may result only when $\frac{t}{2}>M_{I}$.

In case 2 it will be $s=\frac{1}{4}, p=M_{I}-\frac{t}{4}$ and $=\frac{M_{I}}{2}-\frac{t}{8}$. This alternative is feasible only when $M_{I} \geq \frac{t}{4}$. It is easy to show that the firm prefers situation 1 to situation 2 when $\frac{t}{2}>M_{I}$.

In case 3 consumer $z$ indifferent in J will be such that $M_{J}=p+t .(z-s)$. As $p=M_{1}-$ t.s (the consumer at 0 gets no surplus in the solution that maximizes the firm's profits), we obtain from profit maximization $(\pi=p . z)$ that $s=\frac{3 M_{I}-M_{J}}{4 t}$ and $=\frac{\left(M_{I}+M_{J}\right)^{2}}{8 t}$. This alternative requires $\frac{1}{4}<s \leq \frac{1}{2}$ and $\frac{1}{2}<z<1$, i.e., respectively, $t<3 M_{I}-M_{J} \leq 2 t$ and $t<M_{I}+M_{J}<2 t$.

When the firm locates in country $J$ we should distinguish between two possibilities: a) $M_{J} \geq M_{I}-\frac{1}{2}$ and b) $M_{J}<M_{I}-\frac{t}{2}$. With possibility a) it will always be optimal for the firm to decide price and location in such a way that the consumer located at 0 gets no surplus. ${ }^{9}$ However, under possibility b), at the optimal location such that the covered market is connected, the con-

9. Except in the case $M_{J}=M_{I}-\frac{t}{2}$ there will be other locations that, with the same price, will be optimal for the firm. 
sumer located at 0 will get a positive surplus. We consider first the case $M_{J} \geq M_{I}-\frac{1}{2}$.

In case 4-a the problem to solve is the same one than in case 3 and, hence, the solution is the same: $\mathrm{p}=\mathrm{M}_{1}-\mathrm{t} . \mathrm{s}, s=\frac{3 M_{I}-M_{J}}{4 t}, z=\frac{M_{I}+M_{J}}{2 t}$ and

$=\frac{\left(M_{I}+M_{I}\right)^{2}}{8 t}$. H owever, the parameter values for case 4-a should imply location in $\mathrm{J}$ (not in I as in case 3 ). In particular, this alternative requires $\frac{1}{2}<s<\frac{3}{4}$ and $\frac{1}{2}<z<1$, i.e., respectively, $2 \mathrm{t}<3 \mathrm{M}_{1}-\mathrm{M}_{\mathrm{J}}<3 \mathrm{t}$ and $\mathrm{t}<\mathrm{M}_{\mathrm{I}}+\mathrm{M}_{\mathrm{J}}<$ $2 \mathrm{t}$.

In case 5-a we have $\mathrm{p}=\mathrm{M}_{1}-\mathrm{ts}=\mathrm{M}_{\mathrm{J}}-\mathrm{t}(1-\mathrm{s})$ and profit maximization implies $s=\frac{1}{2}+\frac{M_{I}-M_{J}}{2 t}$ and $\quad=p=\frac{M_{I}+M_{J}}{2 t}-\frac{t}{2}$. Notice that $M_{J} \geq M_{I}-\frac{t}{2}$. guarantees $s \leq \frac{3}{4}$. M oreover, this case requires $p \geq 0$, i.e., $t \leq M_{I}+M_{J}$.

Hence, each case is feasible in a particular zone in the space of parameter values. These zones do not intersect for cases 1, 3 and 4-a. On the other hand, the zones of cases 1 and $5-a$ do not intersect as in this latter case we require $t \leq M_{1}+M_{1}$ and this implies $M_{I} \geq \frac{t}{2}$ when $M_{1}>M_{1}$. Finally, we al ready know the result of the comparison between cases 1 and 2 . Therefore it only remains to compare firm profits in case 2 with profits in cases 3, 4-a and 5-a and also firm profits in case 5-a with profits in cases 3 and 4-a.

The expression of $\pi$ in cases 3 and $4-a$ is the same. If we compare this expression with profits in case 2 we obtain that profits in this latter case are higher if and only if $M_{J} \leq-M_{I}+\sqrt{4 t M_{I}-t^{2}}$. On the other hand, if we compare the expression of $\pi$ in cases 3 and $4-a$ with profits in case $5-a$, the latter are always smaller. Finally, profits in case 5-a are higher than profits in case 2 if and only if $M_{J} \geq \frac{3 t}{4}$.

Let us now consider that $M_{J}<M_{I}-\frac{t}{2}$. In this context case 1 is not feasible. We study first case $4-b$. Notice that profit maximization implies that for the optimal $p$ the location $s$ of the firm should be in an interval of locations with left extreme such that $p=M_{J}-t\left(s-\frac{1}{2}\right)$ and right extreme such that $\mathrm{p}=$ $M_{1}-$ ts. As firm profits are the same for any location in this interval we present the algebra for the location in the left extreme of the interval. In case $4-\mathrm{b}$ it is $\mathrm{p}=\mathrm{M}_{\mathrm{J}}-\mathrm{t}$. $\left(s-\frac{1}{2}\right)$ and we obtain from profit maximization $s=\frac{M_{J}}{2 t}+\frac{3}{8}$ and $=\frac{\left(M_{J}+\frac{t}{4}\right)^{2}}{2 t}$. This alternative requires $\frac{1}{2}<s<\frac{3}{4}$, i.e., $\frac{t}{4}<M_{J}<\frac{3 t}{4}$. Hence, profits in case $4-b$ are always lower than profits in case 2 as $\frac{\left(M_{J}+\frac{t}{t^{2}}\right.}{2 t}=\left(\frac{M_{J}}{2}+\frac{t}{8}\right)\left(\frac{M_{J}}{t}+\frac{1}{4}\right)<\frac{M_{J}}{2}+\frac{t}{8}<\frac{M_{I}}{2}-\frac{t}{8}$ where we have used $M_{J}<\frac{3 t}{4}$ in 
the first inequality and $M_{J}<M_{I}-\frac{1}{2}$ in the second inequality. So case 4-b can never be optimal

In case $5-\mathrm{b}$ it is $s=\frac{3}{4}$ and $p=M_{J}-\frac{t}{4}$. From profit maximization we obtain $=p=M_{J}-\frac{t}{4}$ and require $M_{J} \geq \frac{t}{4}$. From here it is clear that profits in case 5-b are higher than profits in case 2 if and only if $M_{J}>\frac{M_{I}}{2}+\frac{t}{8}$. M oreover, the zone of intersection of cases $5-\mathrm{b}$ and 3 is empty as $M_{J}<M_{I}-\frac{t}{2}$ and $3 \mathrm{M}_{1}-\mathrm{M}_{\mathrm{J}}>$ $2 \mathrm{t}$.

\section{A.3 Proof of Proposition 3}

The analysis is analogous to the one developed in the proof of Proposition 1 and illustrated in Figure 1. However, notice that if the tariffs are very high some of the cases that imply exports from one country to the other may not be feasible (zones 3, 3*, 4 and 4* may not exist). On the other hand, when there is a tariff the profits of the firm in cases 1 and 2 do not vary as in these cases production and sales occur in country I. However, profits decrease with the tariff in cases 3, 4 and 5 as there are exports in any of these cases. Hence, if case 1 or case 2 was selected without the tariff the same case ( 1 or 2 with location in I) will be chosen with the tariff

It is immediate to obtain that zone 2 will be larger with tariffs as case 2 occurs when $\frac{t_{\perp}}{2} \leq M \leq \frac{t_{+}+t_{J}}{4}+\frac{f_{\perp}}{2}$. However, zone 3 will be smaller with tariffs as case 3 will happen when $\frac{t_{I}+t_{J}}{4}+\frac{f_{J}}{2}<M<\frac{3 t_{I}+t_{J}}{4}-\frac{f_{J}}{2}$. On the other hand, all pairs $\left(t_{1}, t_{1}\right)$ that are in zone 4 when there are tariffs belong to zones 4 or 5 without tariffs as with tariffs case 4 is feasible if $\frac{3 t_{I}+t_{J}}{4}+\frac{3 f_{I}}{2}<M<\frac{t_{I}+3 t_{J}}{4}+\frac{f_{I}}{2}$. Finally, zones 3* and 4*, if they exist, are located between zones 3 and 4 , i.e., they occur for situations where $\frac{3 t_{t}+t_{J}}{4}-\frac{f_{J}}{2} \leq M \leq \frac{3 t_{t}+t_{J}}{4}+\frac{3 f_{t}}{2}$.

It is not difficult to show that case $3^{*}$ will happen when $\frac{3 t_{l}+t_{J}}{4}-\frac{f_{J}}{2} \leq M$ $\leq \frac{\left(2 f_{l}+f_{J}\right) t_{t}+t_{t} t_{J}+2 f_{I}^{2}}{2\left(f_{l}+f_{J}\right)}$ and case $4 *$ will occur when $\frac{3 t_{I}+t_{J}}{4}-\frac{f_{J}}{2} \leq M \leq \frac{3 t_{I}+t_{J}}{4}+\frac{3 f_{1}}{2}$. Hence, to obtain results i) and ii) we have to compare the regions $M \leq \frac{3 t_{A}+t_{B}}{4}$ and $M \leq \frac{\left(2 f_{l}+f_{J}\right) t_{I}+t_{t} t_{t}+2 f_{I}^{2}}{2\left(f_{t}+f_{J}\right)}$. The slopes ( $\left.\frac{d t_{I}}{d t_{J}}\right)$ of the (straight) lines $\frac{\left(2 f_{I}+f_{J}\right) t_{t}+f_{f} t_{J}+2 f_{I}^{2}}{2\left(f_{I}+f_{J}\right)}=M$ and $3 \mathrm{t}_{1}+\mathrm{t}_{\mathrm{J}}=4 \mathrm{M}$ (the limit from below of zone 3 without tariffs) are $\frac{-f_{I}}{2 f_{I}+f_{J}}$ and $\frac{-1}{3}$, respectively. Hence, when $\mathrm{f}_{\mathrm{I}}<\mathrm{f}_{\mathrm{j}}$ the first line is more horizontal than the second one and when $f_{1}>f_{j}$ the first line is more 
vertical than the second one (the lines are parallel when $f_{l}=f_{f}$ ). The point where these lines cut each other in a Figure with axis $t_{1}$ and $t_{j}$ is $t_{I}=2 M+\frac{2 f_{I}^{2}}{f_{I}-f_{J}}$ and $t_{J}=-2 M-\frac{6 f_{I}^{2}}{f_{I}-f_{J}}$. When $\mathrm{f}_{\mathrm{I}} \geq \mathrm{f}_{\mathrm{j}}$ the value of $\mathrm{t}_{\mathrm{j}}$ corresponding to the cutting point is negative. When $\mathrm{f}_{\mathrm{i}}<\mathrm{f}_{\mathrm{j}}$ the value of $\mathrm{t}_{\mathrm{j}}$ at the cutting point will be lower than $4 M$ if $-\frac{6 f_{I}^{2}}{f_{I}-f_{J}}<6 M$, i.e., if $f_{I}+\frac{f_{I}^{2}}{M}<f_{J}$. Therefore, i) and ii) follow. 